\title{
Implementing ERP Systems in Government: Case Study of Saudi Organization
}

\author{
Abdulelah Almishal and Majed Almashari Alsaud
}

\begin{abstract}
An ERP system has become the most important fields under the Information systems big umbrella. It has a potential market in the Middle East and in Saudi Arabia. Implementing an ERP system in Government has a lot of consideration and faces a lot of challenges. This paper will address major challenges and some key strategies that have to be considered when planning the ERP system. To support the paper, a case study from a large academic government organization is described. This organization has annual budget about 300 million dollar and more than 3000 employees at the different levels of management. We will focus in this paper with their experience including all ERP implementation phases with some discussion of key lessons that can be added to the field.
\end{abstract}

Index Terms-ERP, enterprise systems, business process, government sector, enterprise resource planning.

\section{INTRODUCTION}

Enterprise resource planning (ERP) is an integrated software package including all business functions required to perform the working procedures. Applying this kind of system into government sector requires more effort from different aspects such as change management, business process re-engineering, data migration user training and some other related issues. Based on case study, this paper discusses the main phases of implementing ERP with key strategies to be considered for each phase. Some lessons learned from the case study will be summarized to the conclusion.

\section{GOVERnMENT SECTOR In SAUdi ARABiA}

The technology culture in government organization in Saudi Arabia is still at a beginning level. However, the investment on information technology is reaching 20 billion dollars but the mindset of people in the top management level is still out dated. This mentality actually affects any new changes of new technology, people process and procedures.

Furthermore, the need of having new technology increases rapidly and the competitive against government organizations for moving to technology and providing services online becoming a driver for more investment on the information technology field. This motivation led the most government organization in Saudi Arabia to start a big

Manuscript received April 15, 2014; revised July 28, 2014

Abdulelah Almishal is with the King Abdulaziz City for Sciences and Technologies, Riyadh, Saudi Arabia (e-mail: aalmishal@kacst.edu.sa).

Majed Al-Mashari Al-Saud is with the Department of Information Systems at the College of Computer and Information Sciences of King Saud University, Riyadh, Saudi Arabia (e-mail: malmashari@yahoo.com).
Information Technology transformation projects and one of most important projects is Enterprise Resource planning system ( ERP) implementation that integrate all business process across one integrated enterprise package.

\section{ENTERPRISE RESOURCE PLANNING (ERP)}

Enterprise resource planning is a system that integrates all business activities in one integrated software package. ERP is considered as new technology that includes almost the hall business process and business activities [1]. ERP combines separated business departments such as HR, Finance, Procurement and others with business process that cross this department with workflow in one single system [2]. ERP are packaged software applications (from vendors such as SAP, Oracle, PeopleSoft, and J.D. Edwards) that connect and manage information flows within and across complex organizations, allowing managers to make decisions based on information that truly reflects the current state of their business. These systems also automate complex transaction processes and thus have the potential to reduce costs [3]. In the implementation of ERP systems we face several challenges, such as the high implementation costs and risk factors which must be critically considered. Other problems are difficulties in restoring business processes, insufficient training, preparing and incorporating of users throughout and after the system implementation [4].

ERP is not just an automation of the organization's business process; it gives an opportunity for the organization to re-engineer their business process to reach a success. It provide several advantages such as improved process flow, reduced inventories, better data analysis, better customer service, better enterprise performance and higher efficiency. All of these attract organizations to adopt ERP systems to strongly enter the competitive market [5]. A successful ERP implementation needs a long time and high recourse to be acquired. However, the failure rate in ERP is very high compared with other systems because the complex nature of this system and the high number of persons enrolled in this project from different level of management and among all organization activities. ERP currently become popular in all organization in Saudi Arabia either public or private sector. The ERP market is growing exponentially and most of organization implement ERP or start implementing ERP.

\section{IMPLEMENTING ERP IN GOVERNMENT}

Not like the private sector, the government sector has restricted law and procedures that not fixable and rarely be 
changed. This will affect any ERP implementation project from process point of view. However, the famous ERP software Packages like SAP, Oracle and Microsoft realize this fact and start research about studying government processes and try to produce a standard package for this purpose. The new trend of the government ERP industry is to build a shared platform for each government organization and acting as client-server architecture where the server is located in the information Center or ministry of information technology and provides the ERP services to all government organizations. This approach has a lot of benefits such as:

- Integration of data.

- Public security.

- Reducing implementation and operation cost.

- Reducing time and effort required to start implementing ERP for one organization.

- In Saudi Arabia until now we do not reach this situation. Currently every organization has its own ERP which is different from others. This will cost the government a lot of resources either money or human expertise.

\section{The CASE Study}

Our case study is one of famous research organization in Saudi Arabia [6], [7].

\section{A. The Objective of the Case Study}

This case study is addressing some issues related to this type of organization and showing how the process of the ERP implantation starting from the need of the system until the go-live and support phase. During this demonstration we will focus on the success practice to recommend it and some bad practice to avoid it also to add some contribution to targeted Government sector [8].

\section{B. Data Collection}

This case study is general. The data collected through interviews with project management of the system, the top management in the organization and simple survey are conducted and distributed to the end-users (employees) to measure the user acceptance and get feedback from their experience regarding the system [9].

\section{Organization Technology Background}

Starting at 1977 our organization has been established to satisfy the government needs of research and technology transfer. It's specified on Oil, Power, Space and other technologies. However it is considered as Technology sector but it is not adopting the information technology as it should be.

In 1980's it started using separated legacy systems for specific purposes for Human recourse, Finance, budgeting and warehousing. All of these systems are working stand alone and without any integration. Still they relaying on papers documentation and manual workflows.

In 2000's, the organization replaces some existing systems with new application and infrastructure to satisfy the exponential growth of researches, employees and projects.

From 2009, the top management of the organization realizes that it is the time to establish a new comprehensive solution that integrate all functions units and research department into one Enterprise System or ERP and from that time the motivation has been started.

\section{Needs and Motivation for ERP}

As mentioned in previous section from 2009 the top management decides to move on the enterprise system. From that point they start plan and draw the road map for all organizations systems including ERP, CRM, project management and employee portal to provide an integrated and compatible system sharing same database and technical infrastructure. The figure below shows the structure of the systems according to organization road map (Fig. 1).

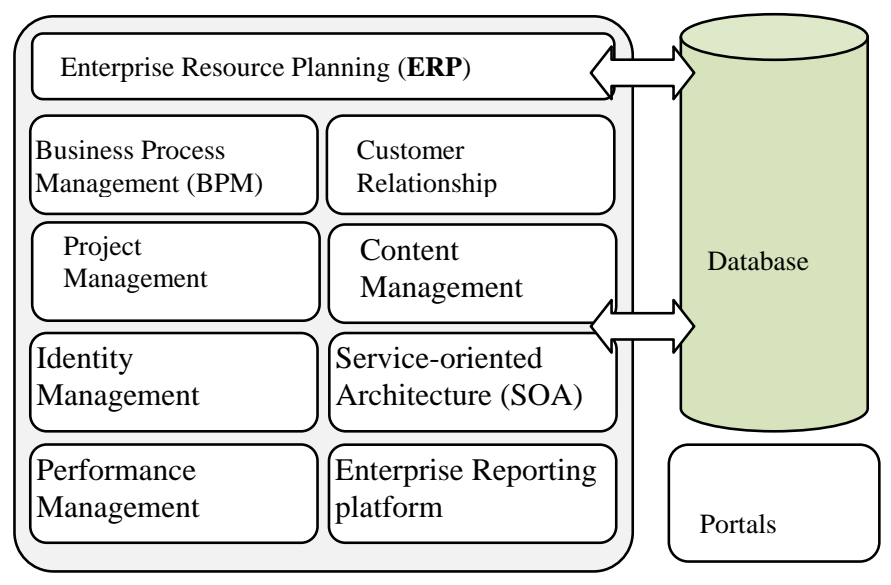

Fig. 1. ERP system structure.

\section{E. Initiation Phase}

Based on the strategic view the top management they start in 2010 initiation phase with high level planning like getting the approval from board of directors, estimate the total budget of the project and reserve the amount from the Government budget. However according to the Project manager interview he is mention that one of the most important challenges is the delay of financial support from ministry of finance because it requires a lot of process, procedures and justification to get them support your project efficiently. It can be summarized that the first strategy of implementing ERP in Government organization is to start accruing budget early to avoid any king of delay that affect the progress of the project.

Also one important decision in this phase is setting methodology of the implementation by implementing as big bang approach or as phased approach. In the case study they chose the phased approach because the environment has no experience of dealing with enterprise systems and they don't have enough background of automating the business. However, it's an expensive option but it is a government organization and they usually don't care more about budget. Furthermore, they decide to choose oracle solutions the reason is the compatibility of the other systems that share same database see the figure above.

\section{F. Planning Phase}

The project is moving on, after we decide to start and get the approval from the authorized person and ensure that the project supported financially, it's the time to start planning. Planning phase concerns about building the teams either 
management team or technical team or consultation team. Choosing the right project manager in one of the critical success factor in Project management in general and in especially for ERP implantation project it's requires high skills person with good background of technology and change management. In our case study they assign the management of the project to external vendor. But unfortunately, they don't manage the project wisely. In the middle of the project the top management decides to move them away and replace them with hiring new high-skills project management team. This decision is critical and important to avoid failure of the implementation.

The management start writing RFPs and making competition to outsource the project the top management chose the cheapest offer that satisfies all requirements mentioned in the RFP [10].

\section{G. Design Phase}

The design phase is the moving deeply to the business processes either analyze the current business process, apply them as is or re-engineering.

One of the major challenges in the government sector the difficulty to change the processes because it requires a letter from prime minister of the government. This issue increases the customization in the system which is not recommended during implementation and also at the next upgrades or enhancements. From our case, the experience shows that the people some time not following either the official process or producers. This issue causes some conflict between the ERP team and the users because people not following any documented business process and they need the system to go with their own way. This is one of the benefits for applying ERP system to government sector is to unify the process and redesign it if required and legal.

\section{H. Realization Phase}

This is the most time-consuming phase in ERP implementation. It is concern about hardware, software installation and some configuration of the system. In our case study, the most critical issue that happens in this phase is localization which means customized tools, solutions that is dedicated to the government sector such as Islamic history because it's the official date system in the government. Another issue such as Arabic language it's difficult to translate every screen in the system even it's supported by oracle. The transition was in parallel way they keep using the old system in parallel with the new system and make sure that the system is stable and reliable.

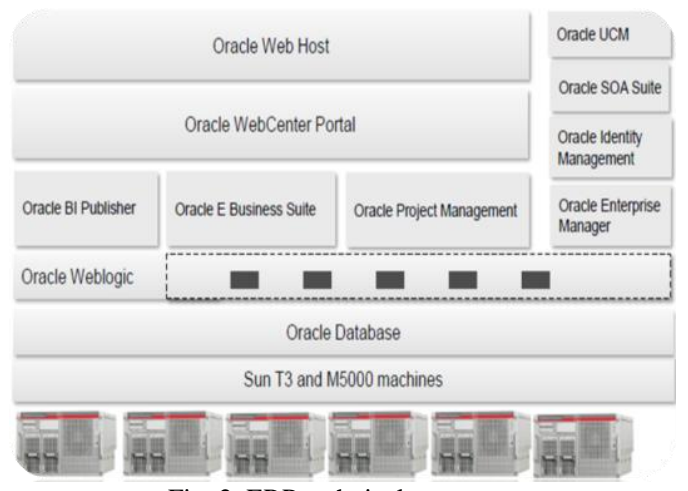

Fig. 2. ERP technical structure.
One of the issues in our case study is the ERP Project not alone it implanted with other systems in parallel sharing same hardware working together virtually. This will make the mission difficult and challenging. See the next figure about the technical structure of the systems (Fig. 2)

\section{Go-Live and Support Phase}

After fighting with software and hardware, and make sure that all system functions work properly we are ready to announce the system ready to use.

The one important lesson in this phase is to keep end user last stage. According to the project manager, it's difficult to start go-live with all end user. It's better to start with key users that evolved in business process first. After that we can broadcast the system to all end users / employees. But unfourtunly, they don't do it well. They announce to all employees at one time and enforce all employees move to new ERP system. Then keep enhancing with new transformation from the old manual way to the ERP way with full support to any one may face some problems.

\section{MAJOR LeSSONS}

From the discussion based on the case study, it can be summarized with a lot of important lessons for effective ERP implementation in government sector:

- To avoid delay of financial or logistics supports keep acting in earlier time.

- Determine your implementation methodology according to your situation. Usually in government sector they go for phased approach.

- Choosing the right project manager with high skilled and enough technology background and aware about the ERP implementation challenges.

- Define the documented business process from the law otherwise use the pest practice from the software package to reduce customization as much as possible.

- To avoid more customization try the readymade package dedicated for government sector if it's available in the market.

- Localization is critical issue in the ERP and need to be considered.

- We you decide to lunch an ERP system it is recommended to start with key users rather than end user.

- Try to apply some change management techniques to help people corporate with you.

\section{SURVEY}

TABLE I: TYPE OF RESPONDENT USERS

\begin{tabular}{lll}
\hline \hline Response & Number & Percentage \\
\hline Employee & 79 & $81 \%$ \\
ERP Business Admin (HR, & 4 & $4 \%$ \\
Finance, Purchasing etc.) & & $14 \%$ \\
Manager/ Supervisor & 14 & $0 \%$ \\
ERP Technical Team & 0 & \\
\hline \hline
\end{tabular}

In this section we want to measure the impact of the system to the user and see either the users are satisfied or not We've 
made a survey distributed over organization. The number of survey exceeding 200 employees with different levels and departments. We got over 97 responses. After collecting and analyzing the data we got the following results:(Table I-Table VIII)

TABLE II: ERP USER TRAINING

\begin{tabular}{lll}
\hline \hline Response & Number & Percentage \\
\hline Trained & 10 & $10 \%$ \\
Not trained & 87 & $90 \%$ \\
\hline \hline
\end{tabular}

\begin{tabular}{lll}
\hline \multicolumn{2}{c}{ TABLE III: FREQUENT OF PROBLEMS } \\
\hline \hline Response & Number & Percentage \\
\hline Always & 31 & $32 \%$ \\
From time to time & 45 & $46 \%$ \\
Only at the beginning & 16 & $16 \%$ \\
Rarely & 5 & $5 \%$ \\
No problem faced & 0 & $0 \%$ \\
\hline \hline
\end{tabular}

\begin{tabular}{lcc}
\hline \multicolumn{2}{c}{ TABLE IV: AFTRE FACING PROBLEM } \\
\hline \hline $\begin{array}{l}\text { Response } \\
\begin{array}{l}\text { The support service is } \\
\text { excellent, the problem } \\
\text { solved quickly. }\end{array}\end{array}$ & 7 & Percentage \\
$\begin{array}{l}\text { The service was good, the } \\
\text { problem solved after } \\
\text { certain time. }\end{array}$ & 46 & $7 \%$ \\
$\begin{array}{l}\text { The service was trouble, } \\
\text { they don't do the job. }\end{array}$ & 41 & $47 \%$ \\
No problem faced & 3 & $3 \%$ \\
\hline \hline
\end{tabular}

\begin{tabular}{lll}
\hline \multicolumn{2}{c}{ TABLE V: OPENIONS ABOUT ERP } \\
\hline \hline Response & Number & Percentage \\
\hline $\begin{array}{l}\text { An important decision and } \\
\text { we have to do it }\end{array}$ & 39 & $40 \%$ \\
$\begin{array}{l}\text { It is a positive step, but not } \\
\text { that much important. }\end{array}$ & 21 & $22 \%$ \\
$\begin{array}{l}\text { No need for ERP, the old } \\
\text { separated system was } \\
\text { working well. }\end{array}$ & 33 & $34 \%$ \\
I don't know & 4 & $4 \%$ \\
\hline \hline
\end{tabular}

\begin{tabular}{lll}
\multicolumn{3}{c}{ TABLE VI: OPINIONS ABOUT ERP IMPACT } \\
\hline \hline Response & Number & Percentage \\
\hline Speed up the process and & 36 & $37 \%$ \\
make it easier & & $51 \%$ \\
Make the business complex & 49 & $9 \%$ \\
Do no thing & 9 & $3 \%$ \\
I don't know & 3 & \\
\hline \hline
\end{tabular}

TABLE VII: ERP USER INTERFACE

\begin{tabular}{lll}
\hline \hline Response & Number & Percentage \\
\hline Excellent & 2 & $2 \%$ \\
Good & 27 & $28 \%$ \\
Not bad & 28 & $29 \%$ \\
Bad & 40 & $41 \%$ \\
\hline \hline
\end{tabular}

From this numbers we can summarize the following point to be recommended to either to our case study or any government organization that might have same problems:

- The numbers shows that the training sessions are not conducted as required it has some impacts the user acceptance.

- Also the number shows that they are lake of operation and support the support was almost trouble.

- According to the project manager interview, no change management activities conducted in the organization to introduce the system. The numbers also implies that.

- Regarding the user interface, I'm also agreed with them. Oracle needs to improve the user interface and performance and I think this one of drawback of oracle ERP solution.

- In general, the users are aware about the ERP and its importance to the organization.

\begin{tabular}{lll}
\multicolumn{3}{c}{ TABLE VIII: ERP GENERAL USER SATISFACTION } \\
\hline \hline Response & Number & Percentage \\
\hline Very Satisfied & 4 & $4 \%$ \\
Satisfied & 19 & $21 \%$ \\
Not that much & 27 & $30 \%$ \\
Not satisfied & 26 & $29 \%$ \\
Disappointed & 15 & $26 \%$ \\
\hline \hline
\end{tabular}

\section{CONCLUSION}

At the end of this paper we have mention the hall story about our case study and share their experience and summarize some important lessons from both side management and users to add some valuable information to any researcher interested in ERP in general and those who are want to implement the ERP system in Government Organization in Saudi Arabia.

\section{ACKNOWLEDGMENT}

I would like to thank the management team of the ERP system in our organization for unlimited support to prepare my paper. Also I would thank my colleagues for participating in the survey.

\section{REFERENCES}

[1] N. Basoglu, T. Daim and O. Kerimoglu; "Organizational adoption of enterprise resource planning systems: A conceptual framework," The Journal of High Technology Management Research, vol. 18, pp. 73-97, 2007.

[2] F. L. Jones and D. V. Rama, Accounting Information Systems: A Business Process Approach, Louisville, Quebec: Thomson South-Western, 2003.

[3] T. H. Davenport, J. G. Harris, and S. Cantrell, "Enterprise systems and ongoing process change," Business Process Management Journal, vol. 10, no. 1, p. 16, 2004.

[4] H. M. Al-Shamaln and A. S. Al-Mudimigh, "The Chang Management Strategies and Processes for Successful ERP Implementation: A Case Study of MADAR," in Proc. International Conference on Computer Communication and Management Proceeding of CSIT, vol. 5, 2011, Singapore.

[5] A. I. ALdayel, M. S. Aldayel, and A. S. Al-Mudimigh, Journal of Information Technology and Economic Development, vol. 2, no. 2, pp. 1-16, October 2011.

[6] M. Saleh, M. Abbad, and M. Al-Shehri, "ERP Implementation Success Factors in Saudi Arabia," International Journal of Computer Science and Security (IJCSS), vol. 7, issue 1, 2013.

[7] S. Anwar and R. Mohsin, "ERP Project Management in Public Sector Key Issues and Strategies," presented at 44th Hawaii International Conference on System Sciences, 2011.

[8] C. Suebsin and N. Gerdsri, "Technology Adoption: A Case Study of ERP Implementation in One of Healthcare Organizations in Thailand," presented at Technology Management for Global Economic Growth (PICMET), Jul. 18-22, Phuket, Thailand. 
[9] A. Bajahzar, A. Alqahtani, and A. Baslem, "A survey study of the Enterprise Resource Planning system," presented at International Conference on Advanced Computer Science Applications and Technologies, 2012, Kuala Lumpur, Malaysia.

[10] K. Sandoe, G. Corbitt, and R. Boykin, Enterprise Integration, p. 2 2001.

Abdulelah Al-Mishal earned his bachelor degree with specialization in Information Systems Department, College of Computer Sciences and Information, King Saud University, Riyadh Saudi Arabia in 2009. And he is currently Studying Master degree from the same department the expected date to finalize the master degree is 2015 .

$\mathrm{He}$ has total 5 years of experience in both public and private sector. This experience in software development for different platforms such as Java, enterprise systems, oracle databases, Microsoft platforms and embedded development using $\mathrm{C}++$. He also has an experience and training in software engineering and project management. Currently, he is working as a researcher in King Abdulaziz City for sciences and technology. His job role includes development within different technologies to satisfy the need for software development in large research projects as well as managing small projects for IT. He has attended different international conferences. He has 3 publications. His area of interests is enterprise applications, data mining, big data, software engineering, knowledgebase systems.

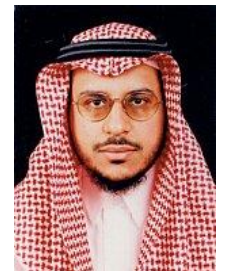

Majed Al-Mashari Al-Saud earned his $\mathrm{PhD}$ from Bradford University in 1999, and is currently a professor of computer information systems at the College of Computer and Information Sciences of King Saud University.

$\mathrm{He}$ is the editor of the Business Process Management Journal and on the editorial board of several other international, refereed journals. He has served on the international scientific committees of several IT conferences in the US and Europe, has also acted as a referee for many scientific papers, and has been published widely in internationally recognized IT journals and conferences. He has a wide range of expertise, both academic and practical, in the areas of software engineering, ecommerce, egovernment, internet deployment, ERP, CRM, BPR, and IT management and strategic planning, amongst others. 